\title{
Oxygen saturation trend and comparison between oxygen saturation levels in normal delivered and caserean section delivered babies within 30 minutes of life
}

\author{
Bhargva $\mathbf{R}^{1}$, Yadav $\mathbf{Y}^{2}$, Yadav $K^{3}$, Sharma $L^{4}$ \\ ${ }^{1}$ Dr Rashi Bhargva, Senior Resident, Department of Paediatric, ${ }^{2}$ Dr Yogesh Yadav, Assistant Professor, Department of \\ Paediatric, ${ }^{3}$ Dr Kavita Yadav, Senior Demonstrator, Department of Physiology, ${ }^{4}$ Dr Lokendra Sharma, Professor, \\ Department of Pharmacology, SMS Medical College, Jaipur, India
}

Address for correspondence: Dr Rashi Bhargav, Email: yoge2501@gmail.com

\begin{abstract}
Objective: To determine normal arterial oxygen saturation ( $\mathrm{SpO} 2)$ trend during first $30 \mathrm{~min}$ of life and to evaluate for difference in $\mathrm{SpO} 2$ trends in healthy term newborns of normal delivered (NVD) and caserean section (CS) and to determine the possible relationship between the normal levels of oxygen saturation and birth weight at 0 and $5^{\text {th }}$ minute of life. Methods: This Prospective Cross-sectional Observational study was conducted in Department of Paediatric Medicine SMS Medical College, Jaipur. Term neonates born by NVD and elective CS were included and readings of oxygen saturation levels were obtained at an interval of 5 minutes up to 30 minutes. Secondary objective is to determine the relation of $\mathrm{SpO} 2$ levels of term newborn with birth weight irrespective of mode of delivery. Results: Difference in values of NVD and CS neonates were statistically significant for $1^{\text {st }}$ and $30^{\text {th }} \min (\mathrm{p}-0.001$ and -0.003 ) respectively. $\mathrm{SpO} 2$ is negatively related to birth weight. Conclusions: The study defines the normal $\mathrm{SpO} 2$ in healthy term newborns of NVD and CS and also concludes that there is significant difference in SpO2 levels at $1^{\text {st }}$ and $30^{\text {th }}$ minute of life in NVD and CS babies. In healthy term newborns, levels of $\mathrm{SpO} 2$ measured at $1^{\text {st }}$ and $5^{\text {th }}$ minute of life are negatively related to birth weight.
\end{abstract}

Keywords: Oxygen saturation, normal vaginal delivery, caesarean section

\section{Introduction}

Transition from a foetus to newborn is a complex physiological process. Pulse oximetry is a simple, noninvasive, reliable method to assess the condition of infant immediately after birth. As respiratory failure is primary cause of mortality, the hypoxia and hyperoxia both can damage the various organs and this can be prevented if arterial oxygen saturation is monitored in normal set range.

NRP 2012 reviewed the target predicted SpO2 levels at set timings after birth [1] The target levels are

$1^{\text {st }} \min 60-65 \%$

$2^{\text {nd }} \min 65-70 \%$

$3^{\text {rd }} \min 70-75 \%$

$4^{\text {th }} \min 75-80 \%$

Manuscript received: $18^{\text {th }}$ July 2016

Reviewed: $30^{\text {th }}$ July 2016

Author Corrected; $10^{\text {th }}$ August 2016

Accepted for Publication: $19^{\text {th }}$ August 2016 $5^{\text {th }} \min 80-85 \%$

$10^{\text {th }} \min 85-95 \%$

During the first few minutes of life, oxygen saturation (saturation by pulse oximetry, $\mathrm{SpO}_{2}$ ) increases from intra partum levels of 30-40\%. [2] In algorithms for neonatal resuscitation published by the International Liaison Committee for Resuscitation, [3] European Resuscitation Council and Australian Resuscitation Council, [4] clinical assessment of an infant's color (a measure of oxygenation) and heart rate are used as major action points.

O'Donnell et al [5] showed that the $\mathrm{SpO}_{2}$ at which observers perceived infants to be pink varied widely, ranging from $10 \%$ to $100 \%$. Assessing color is difficult and therefore is a poor proxy for tissue oxygenation during the first few minutes of life. 
Kattwinkel [6] suggested pulse oximetry may help achieve normoxia in the delivery room. The American Heart Association [7] suggests that "administration of a variable concentration of oxygen guided by pulse oximetry may improve the ability to achieve normoxia more quickly". Leone and Finer [8] advocate a target " $\mathrm{SpO}_{2}$ of 85 to $90 \%$ by three minutes after birth for all infants except in special circumstances"-for example, diaphragmatic hernia or cyanotic congenital heart disease. International surveys show that oximetry is increasingly used during neonatal resuscitation [9].

Pulse oximetry measures $\mathrm{SpO}_{2}$ continuously and non-invasively, without the need for calibration, and correlates closely with arterial oxygen saturation [10]. Pulse oximetry is based on the red and infrared light-absorption characteristics of oxygenated and deoxygenated hemoglobin. A sensor is placed around a hand or foot and two light-emitting diodes send red and infrared light through to a photo detector on the other side. The changes in absorption during the arterial pulsatile flow and non-pulsatile component of the signal are analyzed. $\mathrm{SpO}_{2}$ is estimated from the transmission of light through the pulsatile tissue bed. With each heartbeat, there is a surge of arterial blood that momentarily increases arterial blood volume. This results in more light absorption during surges. As peaks occur with each heartbeat, heart rate can also be measured.

In early studies, investigators placed the sensor over the right Achilles tendon [11] the forefoot[12] or midfoot $[13,14]$. Later studies found that measurements were obtained fastest from the right hand, probably owing to better perfusion, higher blood pressure and oxygenation in preductal vessels "Preductal readings were significantly higher than postductal readings soon after birth ( $\mathrm{p}<0.05)$, By 17 min after birth, there was no longer a significant difference between preductal and postductal measurements $(p<0.05)[5,15]$.

Some studies report the range of $\mathrm{SpO}_{2}$ at 1,5 or $10 \mathrm{~min}$ others report the time taken to reach a predetermined $\mathrm{SpO}_{2}$. These studies show increases in $\mathrm{SpO}_{2}$ from about
$60 \%$ at $1 \mathrm{~min}$, but the levels vary widely, with some infants taking >10 min to exceed $90 \%$. Therefore, it may not be appropriate to identify specific $\mathrm{SpO}_{2}$ levels at certain times after birth, which can be used as a trigger to alter an infant's treatment.

Aim of study was to compare the $\mathrm{SpO} 2$ of healthy newborn term baby born by normal vaginal delivery and elective cesarean section using newer generation pulse oximeter during first 30 minutes of life. Secondary objective is to determine the relation of SpO2 levels of term newborn with birth weight irrespective of mode of delivery.

\section{Materials and Methods}

Present study was conducted in the Department of Paediatric Medicine, SMS Medical College and Hospital, Jaipur. This was a cross-sectional, prospective, observational study. Subjects were newborns of mother who underwent normal vaginal delivery $(n=110)$ and elective caesarean section $(n=80)$ who were not under general anesthesia.

Inclusion criteria were healthy term newborns between gestational age of 37 weeks to 42 weeks, irrespective of gender difference, delivered normal vaginally or by elective caesarean. Newborns with congenital malformations, twin deliveries, retarded growth and Apgar $\leq 6$ at 1 min of life who required resuscitation and oxygen supplementation were excluded. Mothers taking any treatment or with prolonged illness or with severe anemia were excluded.

SpO2 pulse oximeter probe (Ohmeda Tru Sat pulse oximeter) was applied continuously to right palm after thorough wiping and serial recording of pre-ductal arterial oxygen saturation was carried out at intervals of $1,5,10,15,20,25,30$ minutes. Apgar scoring was continued simultaneously along with $\mathrm{SpO} 2$ recordings. After 30 minutes of study newborns were weighed. Statistical analysis with z-test was done for different mean and standard deviation and $\mathrm{p}$ value was derived.

\section{Results}

Below table show that $\mathrm{SpO}_{2}$ was much lower in caesarean-section deliveries, when compared with infants delivered vaginally. The mean (standard error, $\mathrm{SEM}$ ) $\mathrm{SpO}_{2}$ at 1 min was $66.3 \%$ in the caesarean group and $74.5 \%$ in the vaginal delivery group ( $\mathrm{p}<0.001$ ), but by 5 min there was no significant difference in the median for vaginal births.

At 5 min median was $84.4 \%$ and that for caesarean delivery was $82.65 \%$. This postulated that the difference was due to the increased amount of lung fluid after caesarean section. 
Table-1:The SpO2 levels recorded at different timings in newborns of NVD and ECS.

\begin{tabular}{|l|l|l|l|l|l|}
\hline SpO2 LEVELS & NVD & NVD & CS & CS & P value \\
\hline & MEAN & SD & MEAN & SD & \\
\hline $1^{\text {st }}$ min & 74.5 & 13.8 & 66.35 & 11.37 & 0.001 \\
\hline $5^{\text {th }} \min$ & 84.4 & 6.37 & 82.65 & 4.97 & 0.118 \\
\hline $10^{\text {th }} \min$ & 89.14 & 5.5 & 87.95 & 7.94 & 0.303 \\
\hline $15^{\text {th }} \min$ & 94.02 & 3.1 & 92.5 & 4.17 & 0.017 \\
\hline $20^{\text {th }} \min$ & 95.87 & 3.73 & 94.17 & 4.05 & 0.017 \\
\hline $25^{\text {th }} \min$ & 97 & 3.22 & 95.52 & 3.02 & 0.012 \\
\hline $30^{\text {th }}$ min & 97.4 & 2.44 & 96 & 2.79 & 0.003 \\
\hline
\end{tabular}

Table-2: The SpO2 levels recorded according to birth weight

\begin{tabular}{|l|l|l|l|l|l|}
\hline Weight & Total & $1^{\text {st }}$ min & $1^{\text {st }}$ min & $5^{\text {th }}$ min & $5^{\text {th }}$ min \\
\hline & & Mean & Sd & Mean & Sd \\
\hline $1.5-2.49$ & 35 & 75.96 & 10.9 & 85.56 & 5.95 \\
\hline $2.5-3.49$ & 131 & 72 & 12.8 & 83.53 & 6.44 \\
\hline $3.5-4.49$ & 24 & 73 & 9.8 & 84 & 4.22 \\
\hline
\end{tabular}

The above table show that Mean SpO2 was higher in newborn with low birth weight and varied from 75.96 and 85.56 at $1^{\text {st }}$ and $5^{\text {th }}$ minute of life in those with a birth weight of $1.5-2.49 \mathrm{~kg}$ to 72 and 83.53 at $1^{\text {st }}$ and $5^{\text {th }}$ minute of life in those with a birth weight above $2.49 \mathrm{~kg}$.

\section{Discussion}

As the foetus becomes a neonate, a transition from placenta to lung respiration and circulatory changes occur in first few minutes of life. The Apgar score, dependant on the subjective estimation of the examiners, the umbilical arterial and venous cord $\mathrm{pH}$ values, and the pulse oximetry as a non-invasive method for arterial oxygen saturation measurement are only few methods for early detection of hypoxia in the delivery room.

This study was conducted with a sample size of $[n=110$ NVD; $n=80 \mathrm{CS}$ ] in the city of Jaipur defines the normal arterial oxygen saturation levels ( $\mathrm{SpO} 2)$ in normal term newborns within first 30 min of life. The mean SpO2 At $1,5,10,15,20,25$ and 30 minutes among the NVD babies were $74.5 \%, 84.4 \%, 89.14 \%, 94.02 \%, 95.87 \%$, $97 \%, 97.4 \%$, while among the CS babies were $66.35 \%$, $82.65 \%, 87.95 \%, 92.5 \%, 94.17 \%, 95.52 \%, 96 \%$ respectively. Values are statistically significant for $1^{\text {st }}$ and $30^{\text {th }} \min$ ( $\mathrm{p}-0.001$ and -0.003 respectively).

In our study, results demonstrates that infants born by caesarean section have modestly lower oxygen saturations and required prolonged time to reach stable oxygen saturation of $90 \%$ in immediate neonatal period as compared to a newborn born by normal vaginal delivery. This is most likely related to delayed clearance of lung fluid during operative delivery without adequate period of labour. Similar results were obtained in a study done by Yacov et al [16] which said that infants born by caesarean delivery had a 3\% lower $\mathrm{SpO} 2$ than infants delivered by vaginal delivery. other states infants delivered by caesarean section exhibited prolonged values in terms of time to reach $\mathrm{SpO} 2$ levels $>90 \%$ as compared to those infants born by vaginal delivery. Ravikumar Hulsoore et al [11] stated that there is no significant difference in $\mathrm{SpO} 2$ among NVD and $\mathrm{CS}$ whereas Alet Rosvik et al [15] stated $\mathrm{SpO} 2$ was higher in children born by caesarean section than in those delivered vaginally.

Mean SpO2 was higher in newborn with low birth weight and varied from 75.96 and 85.56 at $1^{\text {st }}$ and $5^{\text {th }}$ minute of life in those with a birth weight of $1.5-2.49$ $\mathrm{kg}$ to 72 and 83.53 at $1^{\text {st }}$ and $5^{\text {th }}$ minute of life in those with a birth weight above $2.49 \mathrm{~kg}$. Similar results were obtained in study done by Alet Rosvik et al [15] which states that in healthy newborns, levels of $\mathrm{SpO} 2$ measured between 2 and 24 hour of life are negatively related to birth weight.

The reason for relation between birth weight and $\mathrm{SpO} 2$ in this study is not known. As weight increases with gestational age, differences in $\mathrm{SpO} 2$ could possibly be related to hemodynamic differences related to gestation age. $\mathrm{SpO} 2$ levels are negatively related to birth weight. 
Kopotic and Lindner [17] studied 50 infants at risk for respiratory failure; 25 infants were managed without oximetry and compared with 25 managed with oximetry. Infants managed with oximetry were less likely to be admitted to the special care nursery (32\% v 52\%; $\mathrm{p}=0.04)$.

The studies by Kopotic and Deckardt, although non-blinded and non-randomised, suggest that oximetry can improve short-term outcomes-for example, admission to nursery, the use of oxygen or CPAP. We could find no reports on whether the use of $\mathrm{SpO}_{2}$ measurements immediately after birth alters long-term outcomes.

Conflict of Interest-The author declares no conflict of interest.

\section{Conclusion}

The study concludes that there is a statistically significant difference of $\mathrm{O} 2$ saturations between the neonates born by normal vaginal delivery and caesarean section at $1^{\text {st }}$ and $30^{\text {th }}$ minute of life.

$\mathrm{SpO} 2$ levels are negatively related to birth weight.

Funding: Nil, Conflict of interest: Nil

Permission from IRB: Yes

\section{References}

1. Review of changes in NRP 2012: $6^{\mathrm{TH}}$ edition by Cayce Hendrix, RRT-NPS.

2. East C E, Colditz P B, Begg L M. et al Update on intrapartum fetal pulse oximetry. Aust N Z J Obstet Gynaecol 200242119-124.124 [PubMed]

3. International Liaison Committee on Resuscitation. 2005 International Consensus on Cardiopulmonary Resuscitation and Emergency Cardiovascular Care Science with Treatment Recommendations. Part 7: Neonatal resuscitation. Resuscitation. 2005 NovDec;67(2-3):293-303.

4. Nolan JP, Soar J, Zideman DA, Biarent D, Bossaert LL, Deakin C, Koster RW, Wyllie J, Böttiger B; ERC Guidelines Writing Group. European Resuscitation Council Guidelines for Resuscitation 2010 Section 1. Executive summary. Resuscitation. 2010 Oct;81(10):1219-76. doi:

10.1016/j.resuscitation.2010.08.021.

5. Dawson JA, Davis PG, O'Donnell CP, Kamlin CO, Morley CJ. Pulse oximetry for monitoring infants in the delivery room: a review. Arch Dis Child Fetal Neonatal Ed. 2007 Jan;92(1):F4-7..

6. Kattwinkel J. Evaluating resuscitation practices on the basis of evidence: the findings at first glance may seem illogical. J Pediatr. 2003 Mar;142(3):221-2.

6. American Heart Association American Heart Association (AHA) Guidelines for cardiopulmonary resuscitation (CPR) and emergency cardiovascular care (ECC) of pediatric and neonatal patients: neonatal resuscitation guidelines. Pediatrics 200611710291038.1038 [PubMed]

7. Leone $\mathrm{T}$ A, Finer $\mathrm{N}$ N. Neonatal resuscitation: beyond the basics. NeoReviews 20056e177-e183.e183

8. Leone TA, Rich W, Finer NN. A survey of delivery room resuscitation practices in the United States. Pediatrics. 2006 Feb;117(2):e164-75.

9. Hay WW Jr, Brockway JM, Eyzaguirre M. Neonatal pulse oximetry: accuracy and reliability. Pediatrics. 1989 May;83(5):717-22.

10. Harris A P, Sendak M J, Donham R T. Changes in arterial oxygen saturation immediately after birth in the human neonate. J Pediatr 1986109117119.119 [PubMed] \.

11. Hulsoore R, Shrivastav J, Dwivedi R. Normal oxygen saturation trend in healthy term newborns within 30 minutes of birth. Indian J Pediatr. 2011 Jul;78(7):817-20. doi: 10.1007/s12098-011-0405-1. Epub 2011 Mar 17.

12. Zubarioglu U, Uslu S, Can E, Bülbül A, Nuhoglu A. Oxygen saturation levels during the first minutes of life in healthy term neonates. Tohoku $\mathrm{J}$ Exp Med. 2011;224(4):273-9.

13. House JT, Schultetus RR, Gravenstein N. Continuous neonatal evaluation in the delivery room by pulse oximetry. J Clin Monit. 1987 Apr;3(2):96-100.

14. Meier-Stauss $\mathrm{P}$, Bucher $\mathrm{H} \mathrm{U}$, Hürlimann R. et al Pulse oximetry used for documenting oxygen saturation and right-to-left shunting immediately after birth. Eur J Pediatr 1990149851-855.855 [PubMed

15.Røsvik A, Øymar K, Kvaløy JT, Berget M. Oxygen saturation in healthy newborns; influence of birth weight and mode of delivery. $\mathrm{J}$ Perinat Med. 2009;37(4):403-6. doi: 10.1515/JPM.2009.070. . 
16 Rabi Y, Yee W, Chen SY, Singhal N. Oxygen saturation trends immediately after birth. J Pediatr. 2006 May;148(5):590-
17. Kopotic RJ, Lindner W. Assessing high-risk infants in the delivery room with pulse oximetry. Anesth Analg. 2002 Jan;94(1 Suppl):S31-6.

\section{How to cite this article?}

Bhargva R, Yadav Y, Yadav K, Sharma L. Oxygen saturation trend and comparison between oxygen saturation levels in normal delivered and caserean section delivered babies within 30 minutes of life. Int J Pediatr Res.2016;3(8):635639.doi:10.17511/ijpr.2016.i08.14 